\title{
Sobre orações relativas livres em posição de adjunto: considerações sintático-semânticas acerca das construções com quando e onde $e^{1,2}$
}

\author{
On free relatives in adjunct position: syntactic and \\ semantic considerations about the constructions with \\ quando and onde
}

\section{Paulo Medeiros Junior Unicamp / CNPq}

\begin{abstract}
This paper discusses the structure and the semantics of the Free Relatives headed by quando (when) and onde (where), concerning Brazilian Portuguese data. Issues just as the categorial typology of Free Relatives and their syntactic nature are set on debate and some of the conclusions seem to be the following: the typology of this kind of construction is not as varied as proposed by Bresnan and Grimshaw (1978), and is neither restricted to three specific types, just as set by Larson (1987) (NPs, Aps and AdvPs). The proposal being construed throughout the present paper is set according to the idea that the derivation of Free Relatives involves the incorporation of the heads $\mathrm{C}$ and $\mathrm{D}$, closely related in the relativization process, just as proposed by Medeiros Junior (2005). Free relatives are then DPs in argumental position and PPs in adjunct position. We call free relativization the process that originates theses structures, which, according to this view, can be syntactically nominated according to the syntactic position the take within the sentence: in argumental position, Free Relatives are subject or complement sentences and,
\end{abstract}


contrarily to what is set in Móia (2001), in adjunct position, they are adverbial sentences.

\section{Keywords}

Free relatives; Indirect question; Relativization; Incorporation; DPs; PPs

\section{Resumo}

Este trabalho discute, com base nos dados do português do Brasil (PB), a estrutura e a semântica das orações relativas livres iniciadas por quando e onde. Questões como a tipologia categorial de relativas livres e seu estatuto sintático são postas em debate e algumas das conclusões a que se chegou foram as de que a tipologia categorial desse tipo de construção não é tão variada como propõem Bresnan \& Grimshaw (1978), tampouco se restringe a três categorias específicas tal como proposto em Larson (1987), a saber, NPs, APs e AdvPs. A proposta que por ora elaboramos é formulada com base na proposta de derivação de relativas livres como contendo um amálgama dos núcleos funcionais $\mathrm{C}$ e $\mathrm{D}$, naturalmente envolvidos no processo de relativização, conforme se encontra exposto em Medeiros Junior (2005). Consideramos que relativas livres sejam, portanto, DPs quando em posição argumental e PPs em posição de adjunto. Denominamos relativização livre ao processo de constituição dessas estruturas que, nessa visão, passam a ser classificadas sintaticamente de acordo com a posição sintática na sentença: relativas livres em posição argumental são subjetivas ou completivas e, em posição de adjunto - contrariamente ao que propõe Móia (2001) -, podem ser chamadas adverbiais.

\section{Palavras-chave}

Relativas livres; Interrogativas indiretas; Relativização; Incorporação; DPs; PPs 


\section{Introdução}

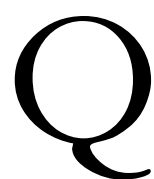

uando o assunto é relativas livres (de agora em diante RLs), vem à baila uma série de questões intrigantes. Entre os estudos linguísticos, um grande mote tem sido o de determinar o estatuto estrutural dessas sentenças, diferenciá-las de construções aparentemente convergentes (as interrogativas indiretas) e definir a tipologia dessas estruturas sintáticas.

A Gramática Tradicional não parece lidar de forma satisfatória com essas sentenças, havendo opiniões discordantes entre os autores. Quando são postas em foco sentenças como as que se apresentam em (1) e (2) logo abaixo, os autores tradicionais não conseguem chegar a um consenso quanto à classificação sintática que elas devem receber. Sejam os dados:

(1) O João chegou [quando você saiu].

(2) A Maria dormiu [onde você se hospedou no ano passado].

Para Cunha e Cintra (1985), numa estrutura como a que se encontra em (1), ocorre uma oração subordinada adverbial temporal. Bechara (1994) também chama de adverbiais as orações iniciadas por quando (temporal) e onde (locativa). Macambira (1997) defende natureza adverbial para essas construções e Kury (1990) - juntamente com esses outros - afirma serem adverbiais as orações desse tipo

Há, entretanto, opiniões como as de Almeida (1961) e Rocha Lima (1994), para quem esse tipo de construção sintática deve ser tratado como oração adjetiva, uma vez que se trata de sentenças que se fazem introduzir, como entendem esses gramáticos, por um pronome relativo, termo que, nessas circunstâncias, condensa mais de uma unidade morfológica, e que deve ser desdobrado para uma adequada interpretação da frase, como em:

(1') O João chegou [[no momento que / na hora que] você saiu].

(2') A Maria dormiu [[no lugar que] você se hospedou no ano passado]. 
Uma primeira questão que se põe é, portanto: qual é a melhor maneira de classificar sintaticamente orações iniciadas por quando e onde?

No campo dos estudos linguísticos, trabalhos como o de Bresnan e Grimshaw (1978) e Larson (1987) discutem a natureza estrutural e a tipologia categorial de relativas livres como as mencionadas acima e nos dados (3), (4) e (5), a seguir. Para as primeiras linguistas, a tipologia de RLs é tão variada quanto as possibilidades de subcategorização do predicador da oração matriz. Para Larson, a tipologia de RLs se reduz a apenas duas: RLs são NPs ou APs. Algumas outras discussões, como a iniciada em Rooryck (1994), têm ainda apresentado relativas livres como CPs comuns, em detrimento de todas as tentativas que se tem constituído para atingir uma distinção entre essas construções e as chamadas interrogativas indiretas.

Com base nessas questões, uma outra pergunta natural a se fazer nesse ponto seria exatamente: o que se pode dizer de fato sobre a tipologia categorial de RLs, ou, pelo menos, o que os dados do português do Brasil revelam sobre a categorização desse tipo de oração?

Muitas propostas sobre o tema, entre as quais as de Rocha (1990), Móia (1996), Caponigro (2001, 2002), Citko (2004), Donati (2006) e Medeiros Junior (2005, 2006), têm buscado estabelecer uma distinção estrutural entre relativas livres e interrogativas indiretas. Para esses autores - diferentemente do que propõe Rooryck - RLs não se constituem em CPs comuns (o que de fato parece acontecer na estruturação de interrogativas indiretas). Para Caponigro, Citko e Medeiros Junior, RLs são estruturas D. Medeiros Junior (2005) argumenta que RLs são DPs complexos, cuja derivação envolve uma operação de movimento de núcleo (de $\mathrm{C}$ para $\mathrm{D}$ ), enquanto as perguntas indiretas são formadas (como tradicionalmente se entende) por movimento de sintagma-wh. ${ }^{3}$

Entretanto, os trabalhos acima mencionados discutem muito mais a estrutura de sentenças com quem, como as que se apresentam em (3), (4) e (5) a seguir, do que as que se constituem com quando e onde, que são o real ponto de avaliação do presente artigo.

(3) A Maria mencionou [quem você conhece].

(4) O Pedro convidou para a festa [quem você indicou].

(5) [Quem lê Guimarães Rosa] é meu amigo. 
Assim, uma outra questão importante que precisa ser levantada é a seguinte: qual é a natureza estrutural das orações introduzidas por quando e onde? O presente trabalho pretende esboçar respostas para essas questões.

\section{Da natureza estrutural de relativas livres}

Orações como as que aparecem nos dados de (1) a (5) têm sido denominadas, na teoria linguística, Relativas Livres; por definição, trata-se de orações relativas que não localizam, no contexto sintático relevante, o antecedente nominal que deveria estar ligado à interpretação da lacuna que se forma no interior desse tipo de oração subordinada.

Os trabalhos se multiplicam e as opiniões se dividem quanto à derivação desse tipo de estrutura e quanto à sua natureza sintática. Para Bresnan \& Grimshaw (1978), a derivação de RLs não envolve movimento; a geração do termo-Wh ocorre na base, na posição de antecedente da sentença, o que viabiliza e garante a ocorrência em RLs do chamado efeito de combinação categorial, totalmente inviabilizado numa proposta com movimento. Para essas autoras, RLs se estruturam como mostra o diagrama em (6), a seguir:

(6)

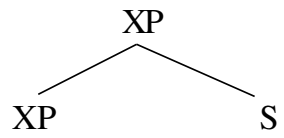

À ideia de Bresnan e Grimshaw opõem-se Groos \& Riemsdijk (1981), para quem o sintagma ou termo-Wh se encontra em Comp e pode ser acessado nessa posição para a satisfação das exigências do predicador da matriz (cf. também HIRSHBÜHLER; RIVERO, 1983 e RIEMSDIJK, 2000). Para Groos e Riemsdijk, RLs apresentam as seguintes possibilidades estruturais:

(7)

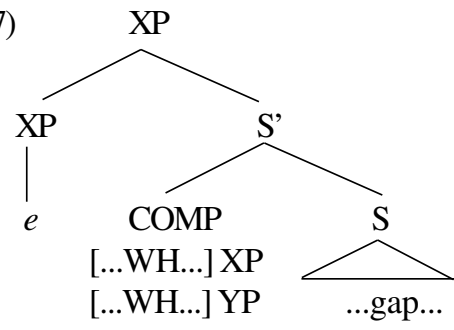

(8)

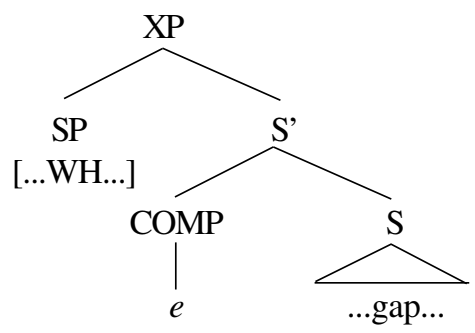


Propostas como a de Rooryck (1994) também apresentam relativas livres como CPs comuns, o que as torna estruturas sintaticamente equivalentes a

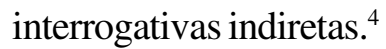

Caponigro (2002) e Citko (2004) analisam relativas livres como DPs. Para Caponigro, RLs são CPs complemento de um D silencioso, que apresentam a seguinte estrutura:

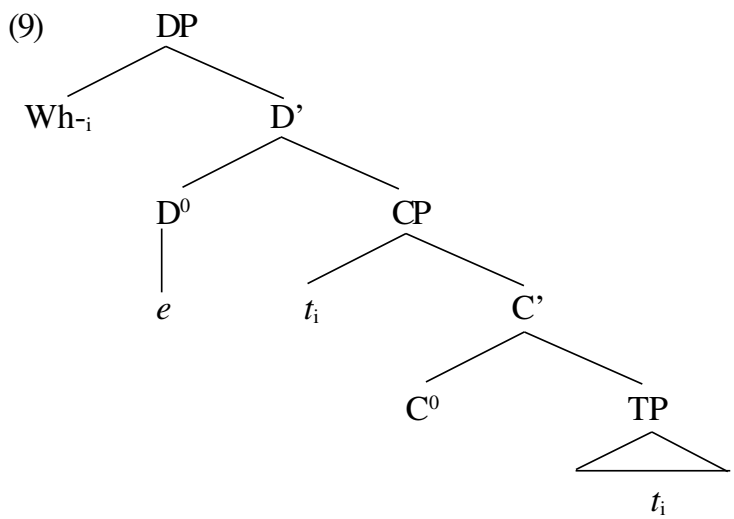

Para Citko (2004), RLs apresentam a seguinte estrutura:

(10)

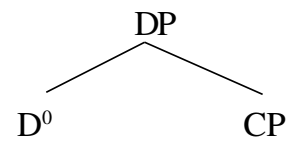

Medeiros Junior (2005) apresenta, com base nos dados do português, uma proposta de estrutura de relativas livres iniciadas por quem, segundo a qual, a derivação dessas construções envolve uma operação sintática complexa de fusão dos núcleos funcionais $\mathrm{C} \mathrm{e} \mathrm{D}$ envolvidos diretamente no processo de relativização (cf. VERGNAUD, 1974; COHEN, 1981; KAYNE, 1994), refletida na forma morfológica do termo-Wh que as integra. Essa proposta prevê que RLs desse tipo sejam estruturas $\mathrm{D}$, em oposição às interrogativas indiretas, interpretadas como CPs comuns. ${ }^{5}$

RLs apresentam, segundo essa visão, a seguinte estrutura: 
(11)

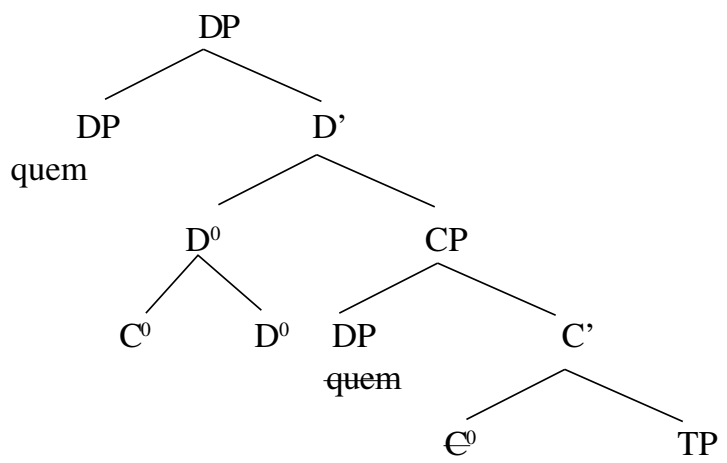

A ideia básica da proposta delineada acima se baseia em dois tipos de evidência:

1 - O fato de existir na derivação um item lexical - quem - que satisfaz as propriedades de dois núcleos funcionais distintos $\mathrm{C}^{0} \mathrm{e} \mathrm{D}^{0}$; esse fato autoriza a postulação de que a forma morfológica desse item reflete uma operação de incorporação de núcleos (nos termos do que propõe Baker (1988)), sendo essa operação específica em relação ao amálgama que caracteriza orações relativas livres, bem como seu comportamento sintático-semântico;

2-Aimpossibilidade de inserção do morfema que e de realização do antecedente em RLs viabiliza a hipótese de que a palavra- $Q u$ corresponde a um amálgama das posições sintáticas em que ocorreriam o antecedente (pronominal) e o morfema relativizador. As posições sintáticas relevantes encontram-se representadas em (12). ${ }^{6}$

(12) a. [O João mencionou [ ${ }_{\mathrm{RL}} \varnothing$ [quem $\varnothing\left[_{\mathrm{IP}}\right.$ você conhece]]]].

b. [O João convidou $\left[_{\mathrm{RL}} \varnothing\right.$ [quem $\varnothing\left[_{\mathrm{IP}}\right.$ trabalha na firma]]]]].

Assume-se de agora em diante que a hipótese de incorporação de C e D esteja correta e toda a argumentação em termos da estrutura de RLs passa a considerar a configuração estrutural apresentada em (11) para a derivação dessas construções. ${ }^{7}$ 


\section{Da tipologia de relativas livres}

\subsection{Análises retrospectivas}

Para além da questão estrutural envolvendo relativas livres, encontra-se a discussão de sua tipologia categorial. Os trabalhos relevantes trazem propostas discordantes acerca da diversidade categorial que esse tipo de estrutura sintática pode apresentar.

Bresnan \& Grimshaw (1978) atestam que a probabilidade de estruturação sintagmática de RLs é tão variada quanto as possibilidades de subcategorização do predicador da matriz. Deste modo, RLs seriam APs, NPs, PPs, AdvPs e assim por diante, a depender das propriedades selecionais do predicador na oração mais alta. Os dados a seguir exemplificam essa ideia:

(13) a. I'll buy $\left[_{\mathrm{NP}}\right.$ whatever you want to sell].

b. John will leave $\left[_{\mathbf{P P}}\right.$ whenever Mary leaves].

c. John will grow $\left[_{\mathbf{A P}}\right.$ however tall his father did].

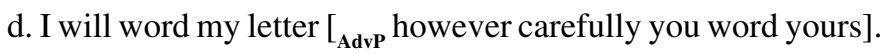

Conforme já se argumentou, a proposta dessas linguistas se baseia numa hipótese sem movimento com a geração do termo-Wh na base, noção que dá suporte a uma ideia da combinação categorial que precisa haver entre o sintagmaWh e a categoria sintática esperada na oração matriz, em decorrência das exigências de subcategorização do predicador mais alto.

Uma análise distinta do fenômeno pode ser encontrada em Larson (1987). Com base na hipótese de ocorrência de um fenômeno conhecido como antecedent contained deletion na derivação dessas estruturas, Larson propõe que a tipologia categorial de relativas livres restrinja-se a apenas duas possibilidades de ocorrência: relativas livres seriam categorialmente NPs ou APs. As primeiras estariam relacionadas a estruturas de natureza $\mathrm{P}$ e as últimas, associadas a estruturas de natureza A.

Larson critica a proposta de Bresnan e Grimshaw, alegando problemas como o de se poder encontrar, nas posições onde se esperariam PPs, AdvPs ou Aps, categorias sintagmáticas absolutamente distintas, como se pode observar nos dados a seguir: 
(14) John will leave

$$
\text { [ }{ }_{\text {AdvP }} \text { subsequently]. }
$$

[PP on Thursday].

$\left[_{N P}\right.$ the day that Max arrives].

[ $_{\text {AdvP }}$ carefully].

(15) I will word my letter $\left[_{\mathbf{P P}}\right.$ in a careful manner].

${ }_{\mathrm{NP}}$ the way that you told me to].

\section{2 $O$ que os dados do português revelam sobre a tipologia de RLs}

A observação detida os dados do PB pode trazer alguma luz sobre a tipologia de relativas livres. Sejam os dados:

(16) a. João indicou para o cargo [quem você conhece].

b. [Quem fez isso] estava fora de si.

c. Dou alimento a [quem não tem condições].

(17) a. Marquei a reunião para [quando você pode].

b. Este é o prazo até [quando se pode entregar o artigo para publicação]

(18) a. Ana dormiu [quando você chegou].

b. Eles só querem sair [quando o dia amanhecer].

c. O Pedro se assustou [quando a porta bateu].

(19) a. Maria dormiu [onde você dormia].

b. João acordou [onde o deixamos].

c. Pedro morreu [onde o encontramos].

Note-se que os dados em (16) e (17) apresentam RLs em posição argumental. Nesses contextos, assume-se que RLs sejam DPs complexos, com o sintagma-Wh em Spec-DP, seguindo a proposta delineada em Medeiros Junior (2005). ${ }^{8}$ A derivação da relativa livre em (16a) se processaria, de forma resumida, da maneira como se mostra em (20). 
(20)

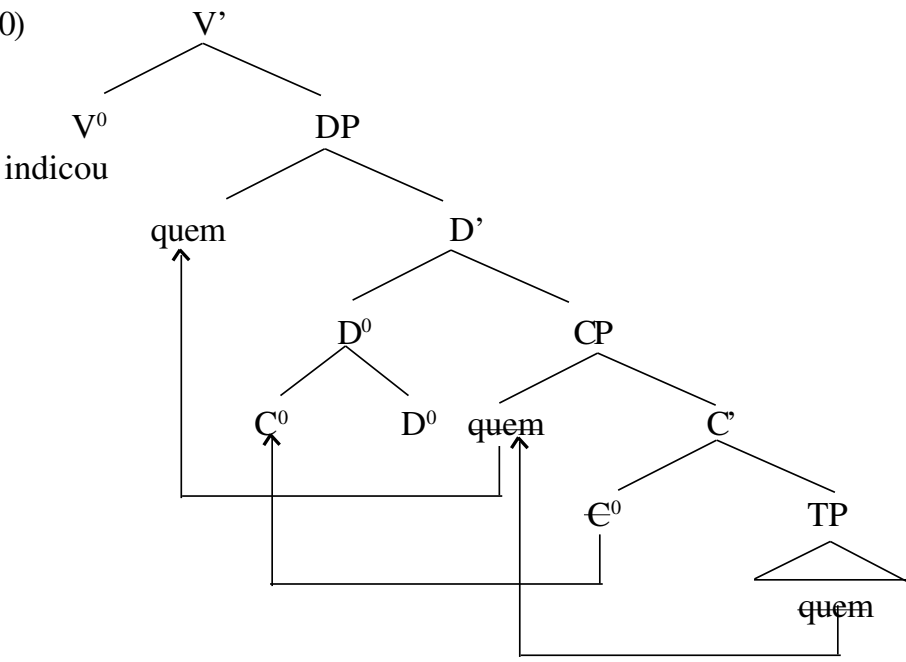

Nos dados em (17), como se pode ver, as RLs são argumentos das preposições na matriz: DPs, portanto. A essas construções aplica-se a mesma análise proposta para as estruturas completivas (16a e 16c), e subjetiva, (16b). Analiticamente, assim como nas sentenças com quem, o termo quando corresponde morfologicamente ao amálgama de o dia em que / o dia que; da mesma maneira o onde das sentenças em (19), corresponde a o lugar em que. $\mathrm{O}$ antecedente e o morfema relativizador encontram-se fundidos em consequência da operação de incorporação de $\mathrm{C} \mathrm{e} \mathrm{D}$, conforme argumentado anteriormente.

RLs como as que aparecem em (18) e (19) teriam uma derivação e uma estrutura semelhantes às que aparecem em (16) e (17). Como se trata de estruturas com o $\mathrm{P}$ lexicalizado, as sentenças iniciadas em quando $(18 \mathrm{a}, \mathrm{b}, \mathrm{c})$ e onde $(19 \mathrm{a}, \mathrm{b}, \mathrm{c})$ se constituem num DP complexo em que os núcleos funcionais $\mathrm{C}$ e D foram amalgamados; o termo-wh encontra-se em Spec-DP e a sentença é argumento da preposição. Essas construções seriam semelhantes às que se mostram a seguir, em que quando e onde introduzem orações em posição argumental:

(21) O João viu [quando a gente chegou].

(22) Eu quero ser [onde você sossega a alma]. 
Casos como os que se mostram em (18) e (19) são diferentes. A numeração $(\mathrm{N})$, que corresponde à derivação dessas sentenças contém um $\mathrm{P}$, mas não um item lexical que o realize fonologicamente. Assim, no decurso da derivação, quando ocorre a concatenação de $\mathrm{P}$, tem-se uma projeção vazia encabeçando a sentença. Conforme proposta de Koopman (2000), explicitada anteriormente, categorias vazias não podem encabeçar projeções sintáticas; assim sendo, o termo-Wh nessas estruturas se desloca para Spec-PP, para o licenciar. Considerando que o termo-Wh passa a satisfazer as necessidades dos núcleos $\mathrm{C}, \mathrm{D}$ e $\mathrm{P}$, propomos que a derivação desse tipo de sentença envolve uma operação de incorporação de núcleos funcionais em que o composto $\mathrm{C}+\mathrm{D}$ é concatenado a $\mathrm{Pe}$, assim, passamos a ter o núcleo complexo $(\mathrm{C}+\mathrm{D})+\mathrm{P}$.

Considerando o PB, em que uma sentença como (18a) corresponde a Ana dormiu [PP n [DP o momento [CP que [VP você chegou]]], ${ }^{9}$ observa-se a interação indispensável entre os núcleos funcionais $\mathrm{C}, \mathrm{D}$ e P; a representação simplificada da derivação da relativa livre em (18a) - segundo a proposta deste trabalho - é apresentada a seguir. ${ }^{10,} 11$

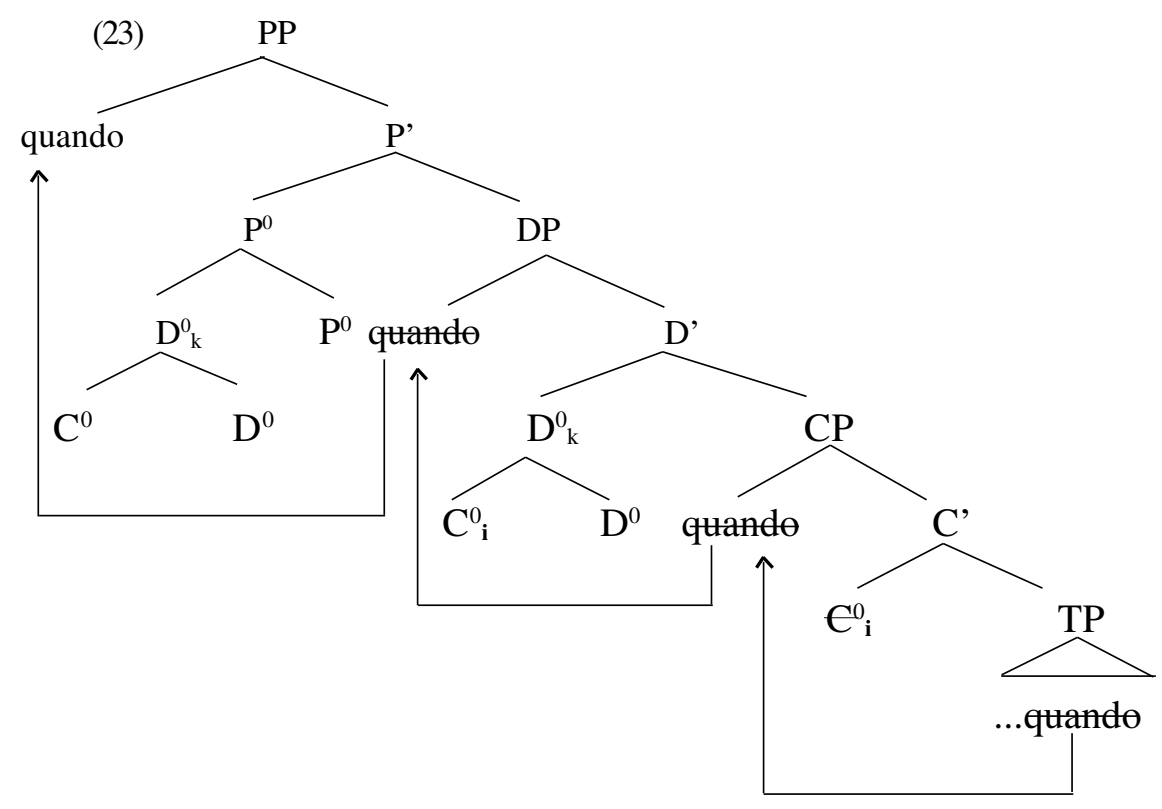


Assim sendo, segundo o que se vê nos dados do $\mathrm{PB}$, as possibilidades de tipificação categorial de RLs em PB resumem-se a apenas duas:

$\rightarrow \quad$ RLs em posição argumental são DPs, resultantes do processo de incorporação de C e D;

$\rightarrow \quad$ RLs em posição de adjunto são PPs com o $\mathrm{P}$ vazio e compreendem um processo de incorporação dos núcleos $\mathrm{C}, \mathrm{D}$ e $\mathrm{P}$, com movimento de $\mathrm{C}$ para $\mathrm{D}$ e de $\mathrm{D}$ para $\mathrm{P}$.

\section{Da classificação sintática}

Na seção de introdução, foi revelada a grande controvérsia que ronda a classificação sintática das orações subordinadas introduzidas por onde e quando na gramática tradicional. Conforme evidenciado anteriormente, há os que tratam dessas construções sintáticas, classificando-as como estruturas adverbiais, e há a opinião de que esse tipo de estrutura provém de um processo de relativização e, assim, precisa ser tratado como uma oração relativa.

A análise dos dados do português do Brasil certamente traz alguma luz sobre essa discussão.

Sejam os dados a seguir do PB:

(24) a. Ana dormiu [cedo / mal / muito / quando você chegou].

b. Eles só querem sair [depois / cedo / mais tarde / quando o dia amanhecer].

(25) a. Maria dormiu [lá / tarde / pouco / em casa / onde você dormia].

b. João chegou [ali / bem / tarde / onde vocês estavam].

Como é possível observar, orações do tipo das que são analisadas neste trabalho são licenciadas nos mesmos contextos sintáticos que advérbios comuns, o que as torna relativas adverbiais (cf. De VRIES, 2002, p. 55). Note-se que, nesses casos específicos, o sintagma-wh exerce no interior da subordinada uma função adverbial.É importante salientar ainda que, conforme observa De Vries (2002), nesse contexto, o papel do núcleo "implícito" é o mesmo na matriz e na relativa, o que de certa forma orienta para uma avaliação do fenômeno conhecido por matching, que se entende afetar relativas livres (cf. BRESNAN; GRIMSHAW, 1978; GROOS; RIEMSDIJK, 1981; HIRSHBÜHLER; RIVERO, 1983; RIEMSDIJK, $2000 \mathrm{e}$ IZVORSKI, 1996; 1998). 
A distribuição pode, portanto, ser argumento em favor de uma análise adverbial para essas construções sintáticas, contrariamente ao que propõe Móia (2001), para quem estruturas como as negritadas em (24) e (25) têm, obrigatoriamente, de ser categorizadas como relativas - adjetivas, nos termos da gramática tradicional.

Nossa proposta não ignora o fato de orações dessa natureza serem constituídas por meio de um processo de relativização, afinal, assim o foi explicitado desde o título. Entretanto, a sugestão é que se dê ao processo de constituição desse tipo de oração a denominação relativização livre e não ao resultado. Relativas livres seriam, assim, estruturas sintáticas que se originam por meio de um processo de relativização, mas que passam a ser etiquetadas sintaticamente de acordo com sua distribuição: aquelas que ocupam posição de sujeito (como em (5)), subjetivas; aquelas que se encontram em posição de complemento (como em (3) e (4)), completivas; aquelas que se encontram em posição de adjunção (como em (18) e (19)), pode-se denominar, dessa forma, adverbiais. ${ }^{12}$

Orações como as mencionadas em (17) são analisadas nesta proposta como completivas comuns, argumentos da preposição da oração matriz, assim como as que se mostram em (21) e (22) são argumentos dos predicadores nas orações mais altas. A constatação é, desse modo, a de que orações subordinadas introduzidas por quando e onde podem aparecem em posição argumental e de adjunção, apesar de serem derivadas sempre por meio de um mesmo processo: a relativização.

\section{Uma breve discussão semântica}

A discussão sobre a semântica de relativas livres também tem ocupado a muitos linguistas (cf. JACOBSON, 1995; GROSU; LANDMAN, 1998; CAPONIGRO, 2003). Em Jacobson (1995) e Grosu \& Landman (1998), a semântica de RLs tem sido analisada como contendo uma operação de maximalização, isto é, a leitura tem de ser obrigatoriamente definida ou universal.

Para Medeiros Junior (2005), os dados do português revelam uma leitura preferencialmente universal para relativas livres em posição argumental, em oposição a uma leitura existencial para as aparentadas interrogativas indiretas. Como se pode ver nos dados a seguir, a interpretação é absolutamente universal para a RL subjetiva e, no mínimo, indefinida para a RL completiva. ${ }^{13}$ 
(26) João entrevistará [quem entrar por aquela porta]. [ $\forall \mathrm{x} /$ entrevistará $(\mathrm{J}, \mathrm{x})]$ $\mathrm{J}=$ João

(27) [Quem lê Guimarães Rosa] é meu amigo. [ $\forall \mathrm{x} / \mathrm{lê}(\mathrm{x}, \mathrm{G})] \mathrm{G}=$ Guimarães Rosa

Interrogativas indiretas, por sua vez, apresentam interpretação existencial para a variável no interior da oração:

(28) Pedro perguntou quem procurava por ele. $[[\exists \mathrm{x} /$ perguntou $(\mathrm{P}, \mathrm{x})]] \mathrm{P}=\mathrm{Pedro}$

O que parece estar acontecendo com as relativas livres em posição de adjunto é exatamente o contrário do que ocorre com RLs em posição argumental. As subordinadas iniciadas por quando e onde parecem apontar para uma leitura existencial, como é possível observar nos dados a seguir, o que as aproxima, em termos de comportamento semântico, das interrogativas indiretas. ${ }^{14}$

(29) O Pedro se assustou [quando a porta bateu]. [ $\exists x /$ momento (x) \& Pedro se assustou em (x)]

(30) O João apareceu [onde nós estávamos]. [ $\exists x$ / lugar (x) \& João apareceu $\mathrm{em}(\mathrm{x})]$

A observação acerca da interpretação de RLs em posição de adjunto representa as primeiras considerações sobre o caso e ainda carece de uma investigação mais aprofundada. $O$ fato é que, seja como for, essas estruturas não parecem apresentar comportamento semântico idêntico, o que se configura em mais uma questão relevante no tratamento da assimetria argumento / adjunto. ${ }^{15}$

\section{Algumas questões conflitantes}

Certos pontos envolvendo o termo-wh em relativas livres ainda se mostram um tanto obscuros, quando são postas em foco sentenças como as que se mostram em (31) e (32) a seguir:

(31) Este é o lugar [onde o deixamos].

(32) Ele apareceu Ø [onde estávamos reunidos].

Como se pode observar, o item lexical onde apresenta comportamento ambíguo no $\mathrm{PB}$, podendo integrar orações relativas típicas, com antecedente, como 
em (31), e relativas livres, como em (32), além - é claro - de poder encabeçar estruturas completivas como em (22).

No caso de quando, a ocorrência com antecedente é possível desde que não haja adjacência absoluta entre o antecedente e o termo-Wh, como se pode ver nos dados (33) e (34) logo abaixo:

(33) Tudo aconteceu naquele dia, quando nos conhecemos.

(34) *Tudo aconteceu no dia quando nos conhecemos.

Uma possibilidade razoável seria considerar que o item lexical onde que aparece em (31) é homônimo ao que se forma na derivação da sentença em (32) que, conforme argumentação anterior, forma-se em sintaxe, como resultado da fusão dos núcleos funcionais $\mathrm{C}, \mathrm{D}$ e $\mathrm{P}$. Ainda assim, porém, não providenciamos uma razão para o comportamento adverso de quando nas mesmas circunstâncias. ${ }^{16}$ Essa questão fica, portanto, em aberto para investigações futuras.

\section{Considerações finais}

Este artigo procurou fazer uma descrição das propriedades sintáticosemânticas das orações relativas livres iniciadas pelos termos quando e onde, tomando como base de apreciação os dados do português do Brasil.

A análise se baseou na ideias de que a derivação de relativas livres envolve uma operação complexa em sintaxe de incorporação dos núcleos funcionais $\mathrm{C}$ e D envolvidos no processo de relativização.

Propomos que as orações relativas livres tenham uma tipologia categorial restrita a apenas duas ocorrências: são DPs, quando em posição argumental, e PPs, em posição de adjunto.

Nossa ideia vai de encontro à de Móia (2001) e à de outros estudiosos que se opõem à classificação sintática desse tipo de oração como subordinada adverbial. Para nós, relativização livre é o nome dado ao processo de constituição da estrutura que, depois de derivada, passa a ser classificada de acordo com a posição sintática que ocupa na sentença; questões como a distribuição, por exemplo, foram consideradas para se afirmar que uma classificação adverbial para esse tipo de oração não seria inapropriada. Assim, RLs em posição argumental podem perfeitamente ser consideradas substantivas e serem classificadas de acordo com a configuração sintática que integrem; do mesmo modo, as que 
aparecem em posição de adjunto podem ser consideradas adverbiais e serem tipificadas de acordo com a circunstância que expressem.

Semanticamente, relativas livres em posição argumental são analisadas como apresentando uma interpretação preferencialmente universal em português, contrariamente ao que acontece com as construções com quando e onde em posição de adjunto, as quais parecem orientar uma interpretação existencial para a variável ligada pelo operador-wh no início da sentença.

Questões como a da proximidade entre o comportamento semântico de relativas livres e interrogativas indiretas e o comportamento sintaticamente ambíguo do termo onde em português ficam em aberto para futuras investigações.

\section{Notas}

${ }^{1}$ Trabalho originalmente apresentado no V Congresso Internacional da ABRALIN. UFMG, Belo Horizonte, 2007.

${ }^{2}$ Meus sinceros agradecimentos a Marcus Lunguinho, pela leitura primeira deste material e a Heidi Harley, por seus comentários preciosos quanto à intuição acerca dos dados.

${ }^{3}$ Em seu trabalho de 2006, Donati chega a conclusões muito semelhantes às proposta em Medeiros Junior (2005). Para essa autora, relativas livres são derivadas por movimento de núcleo. A ideia é a de que o wh se move como núcleo, se adjunge ao $\mathrm{CP}$, modifica as propriedades do alvo e o núcleo $\mathrm{D}$ é que se projeta na constituição final da estrutura.

${ }^{4}$ Uma hipótese de RLs e interrogativas indiretas como construções de estrutura idêntica conduz a uma série de problemas, tais como aventados em Grosu (2002). Sobre a distinção entre interrogativas indiretas e relativas livres, cf. Alvarenga (1981), Rocha (1990) e Medeiros Junior (2005).

${ }^{5}$ Para uma visão de RLs como DPs, ver também Caponigro (2001), (2002) e (2003) e Citko (2004). Uma proposta da derivação de RLs envolvendo movimento de núcleo pode ser encontrada em Donatti (a sair) e Chomsky (2005).

${ }^{6}$ Uma visão mais detalhada dessa proposta encontra-se em Medeiros Junior (2006).

${ }^{7}$ Em Medeiros Junior (2005) e (2006) encontra-se argumentação detalhada sobre a fusão dos núcleos C e D. Com uma análise como essa, é possível dar conta da agramaticalidade dos dados em (i) a seguir, em que se identifica a impossibilidade de se inserir antecedente nominal em RLs, bem como da agramaticalidade de sentenças como a de (ii), por não se poder inserir a partícula que após o sintagma-Wh: 
(i) *O João entrevistou a moça quem cometeu o crime.

(ii) O João entrevistou quem que cometeu o crime.

Como é possível observar, a sentença em (i) é agramatical devido á presença simultânea de a moça (DP que funciona como complemento do verbo da matriz) e quem (termo-qu que compõe a oração relativa). Se se supõe que a palavra-qu subiu para D, a ocorrência do DP a moça nesse contexto sintático passa a ser inviabilizada. Do mesmo modo, se estiver correta a suposição de que em RLs o $\mathrm{C}^{0}$ se incorporou ao $\mathrm{D}$ selecionado pelo predicador da matriz, é possível explicar a impossibilidade da inserção de que nessa posição, pelo fato de o núcleo não se encontrar mais disponível para que possa ser lexicalizado, que é o que mostra o dado em (ii).

${ }^{8} \mathrm{O}$ posicionamento do termo-wh em Spec-DP se daria por uma exigência das línguas de que projeções funcionais não podem ser encabeçadas por um núcleo ou Spec vazio. (Cf. KOOPMAN, 2000).

${ }^{9}$ É importante notar que em PB não se registra a segunda preposição “... no momento em que..." Sobre o apagamento de preposições em relativas do PB, cf. Tarallo (1983), Corrêa (1998) e (2000).

${ }^{10}$ Observe-se que a derivação representada provém da ideia de que o item lexical contido na derivação seja quando, unidade morfológica que contém informações capazes de satisfazer às exigências dos três núcleos funcionais em questão.

${ }^{11}$ No diagrama em (23), as setas mostram o movimento do elemento-Wh, e os índices, o movimento dos núcleos.

${ }^{12}$ Pode-se pensar, alternativamente, que orações iniciadas por quando e onde, como as que se mostram em (i) e (ii) (entre colchetes) sejam consideradas adverbiais comuns que não derivam de um processo de relativização, em consonância com parte da visão tradicional:

(i) O João saiu [quando eu cheguei].

(ii) A Maria morreu [onde eu previ] que ela morreria.

${ }^{13}$ A análise semântica que aqui se apresenta ainda necessita de maior elaboração. Observe-se que parece haver variáveis que condicionam ou favorecem uma leitura existencial, universal ou genérica para RLs, como o tempo verbal e o modo das formas verbais da subordinada.

Nos dados em (i), a seguir, por exemplo, aparecem RLs em posição argumental com uma leitura preferencialmente existencial:

(i) Quem me costuma aborrecer é o João. 
A pseudoclivada, como se pode ver, parece favorecer leitura existencial para o sintagma-wh, assim como a RL em posição de sujeito com verbo no passado:

(ii) Quem escreveu aquele livro acaba de entrar pela sala.

Observe-se, entretanto, que ao termo quem em (ii) acima pode ser associada a estrutura quer que como em "Quem quer que tenha escrito aquele livro acaba de entrar pela sala", o que - segundo Medeiros Júnior (2005) - conduziria a uma leitura universal do termo. Essa questão fica em aberto para debates posteriores. ${ }^{14}$ Emprega-se aqui uma representação lógica informal para facilitar a compreensão.

${ }^{15}$ Observe-se que, nesse caso, também se podem listar dados em que a leitura do sintagma-qu em relativas livres na posição de adjunto apresenta uma leitura universal:

(i) Quando chove, as ruas ficam molhadas.

Essa questão também fica em aberto para discussões mais precisas.

${ }^{16}$ Um problema potencial para essa análise está de fato em considerar que as sentenças com quando e onde sejam derivadas pelo mesmo mecanismo (conforme observado por um dos revisores anônimos), a julgar, por exemplo, pelo fato de que apresentem a diferença de comportamento verificada nos dados em (33) e (34).

O que nos mostra a empiria é que as sentenças iniciadas por quando de fato parecem apresentar comportamento sintático-semântico distinto daquelas que se iniciam por onde. Os dados mostram, por exemplo, uma espécie de dependência temporal entre subordinada e matriz, no caso das sentenças com quando, que não se verifica nas orações iniciadas por onde, como se pode ver em (i) e (ii);

(i) a. *Quando a Maria chegou eu cozinho. / Quando a Maria chegar, eu cozinho.

b. *Quando o Pedro telefonar, eu contei tudo a você. / Quando o Pedro telefonou, eu contei tudo a você.

(ii) a. O João morreu exatamente onde eu moro hoje

b. A Ana sempre se hospeda onde você ficou com sua família no Carnaval de 1988.

Por razões óbvias, matriz e principal em (i) estão ligadas numa noção temporal forte, o que pode vir a ser um indício de que se trata de uma construção de natureza absolutamente adverbial em sua constituição. Quanto a isso, a presente análise se posiciona de forma favorável a denominar tais construções adverbiais, embora Móia (2001) argumente insistentemente sobre a natureza relativa dessas estruturas, conforme argumentado anteriormente. 
Assim sendo, a distinção sintática que se observa em (33) e (34) - a qual parece apontar de forma inequívoca para uma separação entre as estruturas com quando e onde - bem como o que se vê em (i) e (ii) nesta nota, sugere que essas construções talvez devessem receber um tratamento diferenciado. Essa questão, apesar de não invalidar uma proposta de incorporação de núcleos para as sentenças que se iniciam com quando, traz algumas questões intrigantes para a discussão que, por ora, ficam em aberto para serem retomadas em considerações futuras.

\section{Referências}

ALMEIDA, N. M. de. Gramática metódica da língua portuguesa. 13. ed. São Paulo: Saraiva, 1961.

ALVARENGA, D. Sobre interrogativa indireta no português. 1981. Dissertação (Mestrado) - Faculdade de Letras da UFMG, Belo Horizonte, 1981.

BAKER, M. Incorporation. Chicago: The University of Chicago Press, 1988.

BECHARA, E. Moderna gramática portuguesa. 35. ed. São Paulo: Companhia Editoria Nacional, 1994.

BRESNAN, J.; GRIMSHAW, J. The Syntax of English Free Relatives. Linguistic Inquiry 9, p. 331-391, 1978.

CAPONIGRO, I. On the semantics of indefinite free relatives. In: KOPEN, M. v., SIO, J.; De VOS, M. (Ed.). Proceedings of ConSOLEX, Leiden: SOLE. p. 49-62, 2001.

CAPONIGRO, I. Free Relatives as DPs with a Silent D and a CP Complement. In: SAMIIAN, V. (Ed.). Proceedings of the Western Conferences on Linguistics, 2000 (WECOL 2000), Fresno, California: California State University, 2002.

CAPONIGRO, I. The Semantic contributions of Wh-words and Type Shifts: Evidence from Free Relatives Cross linguistically. Proceedings of Semantics and Linguistic Theory (SALT) XIV. Itaca, NY: CLS Publications, Cornel University, 2003.

CHOMSKY, N. On Phases. ms. Massachusetts Institute of Technology, Cambridge, 2005 .

CITKO, B. On Headed, Headless and Light-headed Relatives. Natural Language and Linguistic Theory, 22, p.95-126, 2004.

COHEN, M. A. de M. Orações relativas restritivas em português - registro formal e informal. 1981. Dissertação (Mestrado) - Universidade Federal de Minas Gerais, Belo Horizonte, 1981. 
CORRÊA, V. R. Oração relativa: o que fala e o que se aprende no português do Brasil. 1998. Tese (Doutorado) - Unicamp, Campinas, 1998.

CORRÊA, V. R. Variação sintática em Portugal e no Brasil: orações relativas. In: Actas do XVI Encontro Nacional da Associação Portuguesa de Linguística, p. 615-665. Lisboa: APLe Colibri, 2000.

CUNHA, C.; CINTRA, L. Nova gramática do português contemporâneo. 3. ed. Rio de Janeiro: Nova Fronteira, 1985.

De VRIES, M. The Sintax of Relativization. Utrecht: Lot, 2002.

DONATI, C. On Wh-head movement. In: CHENG, Lisa Lai-Shen; CORVER, Norbert (Ed.). Wh-movement: moving on. Cambridge, MA: MIT Press, p 21-46, 2006.

GROSS, A.; RIEMSDIJK, H. v. Matching Effect in Free Relatives: A parameter of Core Grammar. In: Proceedings of Pisa Coloquium on Markedness, Annali dela Scuola Normale Superiore, Pisa, 1981.

GROSU, A. Strange Relatives at the Interface of two Milenia. Glot Intenational v. 6, n. 6, 2002.

GROSU, A.; LANDMAN, F. Strange relatives of the third kind. Natural Language Semantics, 6, p. 125-170, 1998.

HIRSHBÜHLER, P.; RIVERO, M. L. Remarks on free relatives and matching phenomena. Linguistic Inquiry, 14 (3), 1983.

IZVORSKI, R. (Non-) Matching Effects in Free Relatives and pro-drop. University of Pennsylvania, USA, MS, 1996.

IZVORSKI, R. Non-Indicative Wh-Complements of Possessive and Exitential Predicates.In: TAMANJI, P. N.; KUSUMOTO, K. (Ed.). Proceedings of NELS 28, p. 159-173, 1998.

JACOBSON, P. On the Quantificational Force of English Free Relatives. In: BACH, E. et al. (Ed.). Quantification in Natural Languages. Kluwer, Dordrecht, p. 451-486, 1995.

KAYNE, Richard. The Antisymmetry of Syntax (Linguistic Inquiry Monographs, 25). Cambridge, MA: MIT Press, 1994.

KOOPMAN, H. The Spec Head Configuration. In: KOOPMAN, H. The Syntax of Specifiers and Heads: Controlled essays of Hilda J. Koopman. London-New York: Routledge, 2000.

KURY, A. da G. Novas lições de análise sintática. 4. ed. São Paulo: Ática, 1990. 
LARSON, Richard K. "Missing Prepositions" and the Analysis of English Free Relative Clauses. Linguistic Inquiry, 18 (2), 1987.

MACAMBIRA, J. R. A estrutura morfossintática do português. 8. ed. São Paulo: Pioneira, 1997.

MEDEIROS JUNIOR, P. Sobre sintagmas-Qu e relativas livres no português. 2005. Dissertação (Mestrado) - Universidade de Brasília, Brasília, 2005.

MEDEIROS JUNIOR, P. Relativas livres: uma proposta para o português. Revista de Estudos da Linguagem, Belo Horizonte, UFMG, 2006.

MÓIA, T. A sintaxe das orações relativas sem antecedente expresso no português. In: Quatro estudos em sintaxe do português. Lisboa: Edições Colibri, 1996.

MÓIA, T. Aspectos sintáticos e semânticos das orações relativas com como e quando. In: Actas do XVI Encontro Nacional da Associação Portuguesa de Linguística, Lisboa, 2001.

RIEMSDIJK, H. v. Free Relatives SynCom Case 44, 2000.

ROCHA, Mari Lucia D. F. Sintagmas QU em interrogativas indiretas e relativas livres do português. 1990. Dissertação (Mestrado) - Universidade de Brasília, Brasília, 1990.

ROCHA LIMA, C. H. da. Gramática normativa da língua portuguesa. 32. ed. Rio de Janeiro: José Olympio, 1994.

ROORYCK, J. Generalized Transfornations and the Wh-cycle: Free Relatives as Bare Wh-CPs. Groninger Arbeiten zur germanistischen Linguistik 37, p. 195-208, 1994.

TARALLO, F. L. Relativization Strategies in Brazilian Portuguese. 1983. PhD Dissertation (PhD) - University of Pensylvania, 1983.

VERGNAUD, J. R. French Relative Clauses. Doctoral Dissertation, MIT, 1974. 